\section{References}

1. Craig JM, Darling RC, Rothney WB. Total pulmonary venous drainage into the right side of the heart; report of 17 autopsied cases not associated with other major cardiovascular anomalies. Lab Invest. 1957;6:44-64.

2. Bharati S, Lev M. Total anomalous pulmonary venous drainage. In: Bharati S, Lev M, eds. The pathology of congenital heart disease: a personal experience with more than 6,300 congenitally malformed hearts. Armonk (NY): Futura Publishing; 1996. 609-26.
3. Cameron D. Repair of unusual types of total anomalous pulmonary veins. Oper Tech Thorac Cardiovasc Surg. 2001;6:50-7.

4. Yun TJ, Coles JG, Konstantinov I, Al-Radi OO, Wald RM, Guerra V, et al Conventional and sutureless techniques for management of the pulmonary veins: evolution of indications from postrepair pulmonary vein stenosis to primary pulmonary vein anomalies. J Thorac Cardiovasc Surg. 2005;129: $167-74$.

\title{
A novel hybrid technique for transcatheter pulmonary valve implantation within a dilated native right ventricular outflow tract
}

\author{
Frances C. Travelli, MD, ${ }^{\mathrm{a}}$ Cynthia S. Herrington, MD, ${ }^{\mathrm{b}}$ and Frank F. Ing, MD, ${ }^{\mathrm{a}}$ Los Angeles, Calif
}

Since the Food and Drug Administration approval of the Melody transcatheter pulmonary valve (Medtronic Inc, Minneapolis, Minn) in 2010, multiple reports of its use to treat dysfunctional right ventricle-to-pulmonary artery conduits have been published. ${ }^{1,2}$ However, use of this valve is limited to 16- to 22-mm diameter conduits or bioprosthetic valves. ${ }^{1}$ The Melody valve is not recommended for native right ventricular outflow tracts (RVOTs) because of its general dilated anatomy and high compliance of the native tissue, rendering a high risk of device malposition or embolization. We report a novel hybrid technique of Melody valve implantation within a dilated native RVOT.

\section{CLINICAL SUMMARY}

A 17-year-old male patient with tetralogy of Fallot status post-transannular patch repair at age 1 month presented with severe pulmonary insufficiency and increasing exercise intolerance. Cardiac magnetic resonance imaging showed a markedly dilated right ventricle, right ventricular indexed end-diastolic volume $194 \mathrm{~mL} / \mathrm{m}^{2}$, regurgitant fraction $50 \%$, and preserved biventricular function. The dilated native RVOT diameter was $24 \mathrm{~mm}$. Because of mild developmental delay resulting from a cerebral infarct after his initial tetralogy of Fallot repair, the decision was made to

\footnotetext{
From the Divisions of Cardiology, Departments of Pediatrics ${ }^{\mathrm{a}}$ and Cardiothoracic

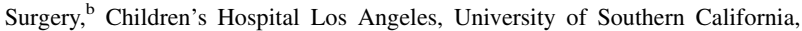
Los Angeles, Calif.

Disclosures: Cynthia S. Herrington and Frank F. Ing report consulting fees from St. Jude Medical. All other authors have nothing to disclose with regard to commercial support.

Received for publication March 7, 2014; revisions received April 17, 2014; accepted for publication April 24, 2014; available ahead of print June 11, 2014.

Address for reprints: Frank F. Ing, MD, Children's Hospital Los Angeles, 4650 Sunset Blvd, MS\#34, Los Angeles, CA 90027 (E-mail: fing@ chla.usc.edu).

J Thorac Cardiovasc Surg 2014;148:e145-6

$0022-5223 / \$ 36.00$

Copyright (c) 2014 by The American Association for Thoracic Surgery

http://dx.doi.org/10.1016/j.jtcvs.2014.04.046
}

avoid the risks of cardiopulmonary bypass and proceed with the hybrid approach for Melody valve implantation.

After a midline sternotomy and exposure of the RVOT, a $12 \mathrm{~mm}$ in width short "tube" was cut from a 22-mm polytetrafluoroethylene graft (Gore-Tex, WL Gore \& Associates Inc, Flagstaff, Ariz). This tube was then cut and wrapped around the main pulmonary artery (MPA) just above the pulmonary annulus to "restrict" the MPA diameter to 22 mm (Figure 1). The width and location of the tube were carefully selected by dissecting the MPA from the aorta and measuring the distance from the pulmonary annulus to the take-off of the right pulmonary artery. The coronary

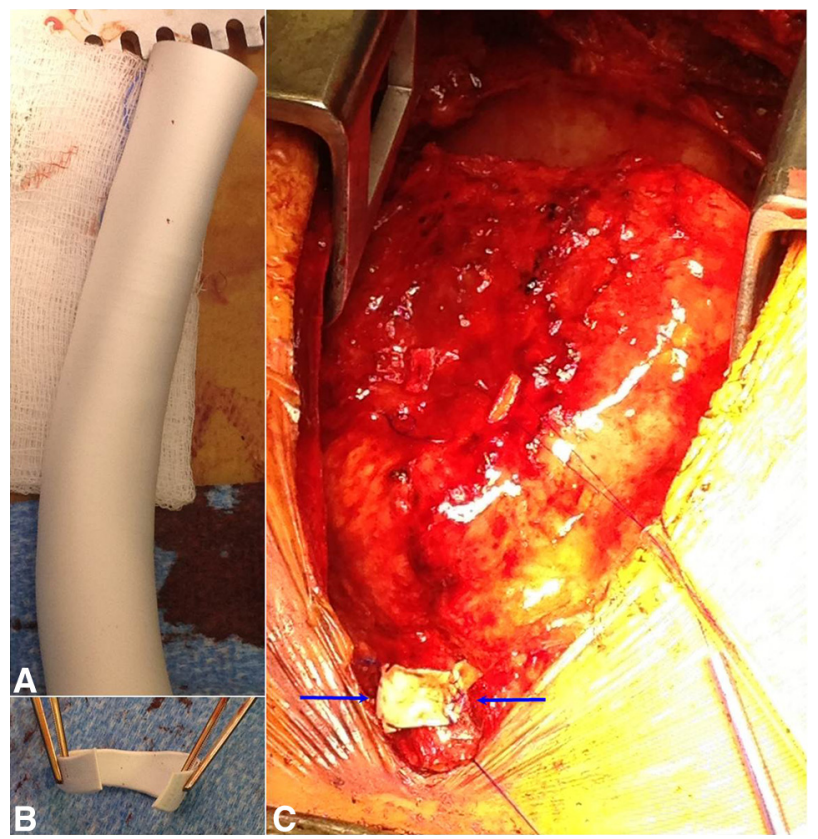

FIGURE 1. A, A 22-mm polytetrafluoroethylene tube. B, A 12-mm width short tube cut and opened. $\mathrm{C}$, The tube is placed around the RVOT (blue arrows) to be used as the landing zone for the Melody valve (Medtronic Inc, Minneapolis, Minn). 


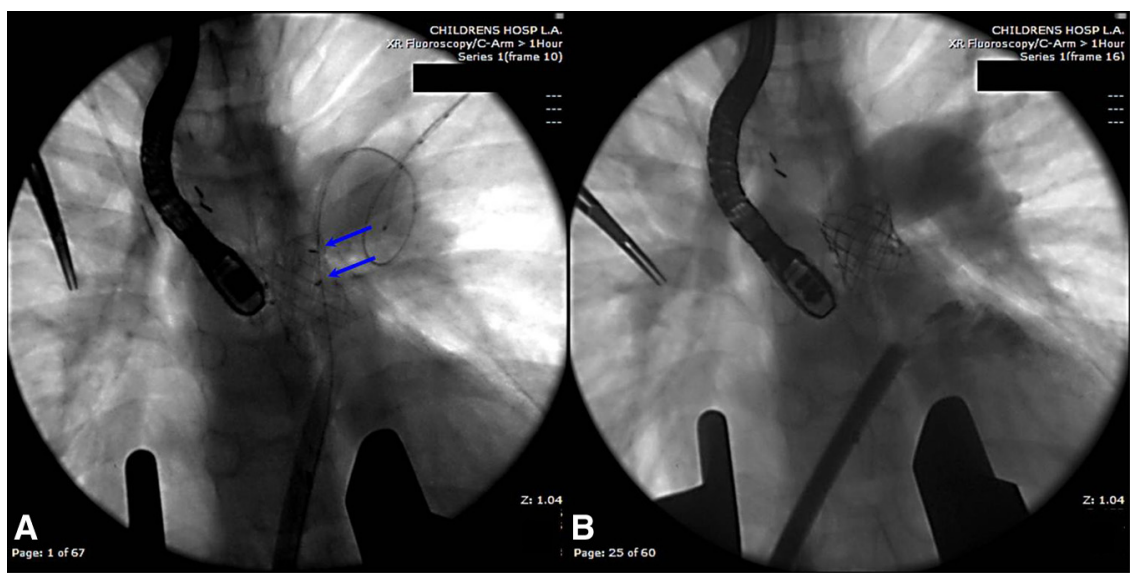

FIGURE 2. A, Radiographic image post-stent placement of RVOT with a Palmaz stent (Cordis Johnson \& Johnson Medical NV, Bridgewater, NJ) using 4 small clips (blue arrows) as radio-opaque markers for the location of the landing zone. B, Radiographic image post-Melody valve implantation telescoped through the Palmaz stent.

artery course was carefully assessed to ensure that the band would not cause compression. Four small metal clips were placed on the band anteriorly to use as radio-opaque markers on fluoroscopy (Figure 2,A). Once the entry site for the perventricular approach into the RVOT was identified, a purse-string suture was placed around the small incision site for introduction of a $22 \mathrm{~F}$ short sheath into the RVOT followed by passage of a 0.035 -inch Teflon wire into the left lower PA. With a portable C-arm, angiography was performed to assess both sheath and wire positions in relationship to the "landing zone" in the MPA. Initially, a 4010 Palmaz XL stent (Cordis Johnson \& Johnson Medical $\mathrm{NV}$, Bridgewater, NJ) was crimped onto a 24-mm BIB balloon (NuMED Inc, Hopkinton, NY) and deployed in the RVOT across the polytetrafluoroethylene "band" to affix the remnant pulmonary valve leaflets in the outflow tract and to provide additional structural support before Melody valve implantation (Figure 2, A). Next, the Melody valve was loaded onto a 24-mm BIB balloon and delivered in the same fashion through the sheath telescoping into the newly implanted stent. Post-implant angiograms confirmed the optimal Melody valve position (Figure 2, B). By transesophageal echocardiography, there was no regurgitation or perivalvular leaks. The sheath was removed, and the purse-string was tied to achieve hemostasis. No bypass was used during the procedure. The patient was extubated and weaned to room air within 1 day, transferred to the step-down unit within 2 days, and discharged to home in 4 days.

\section{DISCUSSION}

As physicians gain experience with the Melody valve, some of the initial limitations have been overcome with novel techniques. Although native outflow tracts generally are not amenable to Melody valve implants because of its large diameter $(>22 \mathrm{~mm})$ and high compliance, there are scattered reports of successful implants in rare cases of stenotic native RVOTs. A recent report showed that the Melody valve remains competent even when overdilated with a 24-mm balloon, which can extend its use to slightly larger diameters. ${ }^{3}$ Current experiments with outflow reducers are under way, but none are available for general use. In small-sized patients or as a bailout for failed percutaneous attempts, hybrid techniques have been used to successfully implant the Melody valve. ${ }^{4,5}$ To date, the technique of a surgically placed external band to serve as an anchor for a Melody valve implant has been trialed only in an animal model; however, there are no known reports of using this technique in humans. ${ }^{6}$ Such novel techniques can expand the use of the Melody valve for implantation in native outflow tracts when potential bypass complications are high.

\section{References}

1. Gillespie MJ, Rome JJ, Levi DS, Williams RJ, Rhodes JF, Cheatham JP, et al. Melody valve implant within failed bioprosthetic valves in the pulmonary position: a multicenter experience. Circ Cardiovasc Interv. 2012;5:862-70.

2. McElhinney DB, Hellenbrand WE, Zahn EM, Jones TK, Cheatham JP, Lock JE, et al. Short- and medium-term outcomes after transcatheter pulmonary valve placement in the expanded multicenter US melody valve trial. Circulation. 2010;122:507-16.

3. Cheatham SL, Holzer RJ, Chisolm JL, Cheatham JP. The Medtronic Melody transcatheter pulmonary valve implanted at $24-\mathrm{mm}$ diameter-it works. Catheter Cardiovasc Interv. 2013;82:816-23

4. Berman DP, Burke R, Zahn EM. Use of a novel hybrid approach to salvage an attempted transcatheter pulmonary valve implant. Pediatr Cardiol. 2012;33: 839-42.

5. Holoshitz N, Ilbawi MN, Amin Z. Perventricular Melody valve implantation in a $12 \mathrm{~kg}$ child. Catheter Cardiovasc Interv. 2013;82:824-7.

6. Boudjemline Y, Schievano S, Bonnet C, Coats L, Agnoletti G, Khambadkone S, et al. Off-pump replacement of the pulmonary valve in large right ventricular outflow tracts: a hybrid approach. J Thorac Cardiovasc Surg. 2005;129:831-7. 